\title{
THE EPIDEMIOLOGY OF MALARIA IN UNIVERSITY OF AGRICULTURE MAKURDI HEALTH CENTRE, MAKURDI, NIGERIA.
}

\author{
${ }^{1}$ Saganuwan, A. S. ${ }^{2}$ Adelaiye, P. O., \\ 'Departments of Veterinary Physiology, Pharmacology and ${ }^{2}$ Biochemistry, College of Veterinary Medicine, and \\ Stat/Maths/Computer Science, ${ }^{3}$ College of Agricultural Science, ${ }^{4}$ University of Agriculture, P.M.B. 2373, \\ Makurdi, Benue State, Nigeria
}

•Correspondence: E-mail:pharn_saga@yahoo.com Telephone:2348027444269, 234802675993

\begin{abstract}
The epidemiological study of Malaria in University of Agriculture Makurdi health center was carried out between January 1998 and December 2005. The Malarial cases were sorted out from other medical cases. Data of males were separated from those of females. Data for each year under age groups $0-9,10-19,20-29,30$ $39,40-49,50-59,60-69$, were differentiated. The results revealed the highestincidence of malaria in 2005 , but males were more affected during the period under review $(p<0.05)$. Age wise, those in age group $(20$ - 29) had the highest incidence $\left(149.80^{\circ}\right)$ followed by those in age group $(0-9)$, which had $\left(78.20^{\circ}\right)$, then age group (30 39 ), which had $\left(70.80^{\circ}\right)$ and lastly the age group $(10-19)$ had $\left(60.10^{\circ}\right)$. But those in the age groups $(40-49)$, (50 $59)$ and $(60-69)$ had very low malarial infection rates $\left(0.8^{0}\right),\left(0.3^{0}\right)$ and $\left(0.0^{\circ}\right)$ respectively. The phenomenon is referred to as beneficial and risky reverse opportunities in favour of the old ones as against the young ones. This however depends on environment..
\end{abstract}

Keywords: $\quad$ Epidemiology, Malaria, Nigeria

\section{INTRODUCTION}

Human malaria has been recognized since the earliest period, and the occurrence of mosquitoes trapped in amber suggests its prevalence in pre-historic times (1). The first evidence that plasmodium was the etiologic agent of malaria was recognized by Charles Iaveran in 1880 as he scanned a live mount of a febrile soldier's blood at Constatine Hospital in Algeria (2). Malaria in man is caused by four species of plasmodium, $P$. vivax, $P$. malaria, $P$. ovale and $P$. falciparum (3). The last named is not only the most common in Africa but is the most virulent and enjoys the reputation as the greatest killer of mankind, being particularly dangerous to children (4) and responsible for all serious complications and deaths (5).

According to World Health Organization (WHO), each year 300 to 500 million people living in the tropics and sub-tropics become infected with malaria. Nearly 3 million, mostly children die. About 1.5 billion people live in the regions where malaria is endemic. Those regions are Africa, India, South East Asia, and South America $(6,7,8,9)$. About $93 \%$ of the 550 million people living in Africa are at risk of malaria and over $90 \%$ of the $300-500$ million clinical cases are reported from Africa (10). Ukpai and Ajoku 2001 reported high prevalence rates of malaria in 
Owerri (75\%) and Okigwe (85.5\%) (11). Malaria is directly responsible for one in five childhood deaths in Africa and its resurgence in Africa contrasts dramatically with the global decline in mortality since $1900(12)$

Fifty percent ( $50 \%$ ) of Nigerian population experience at least one episode of malaria each year, the financial implication could amount to $\$ 400$ million every year (13).

In Nigeria today, malaria affects more people than it did in the $60 \mathrm{~s}$. The Federal Ministry of Health reports that one in four people suffer from malaria fever at one time or the other, while up to 1.2 million children (under the age of five) still die of malaria annually $(3,4)$ and the numbers affected are growing "remorselessly" (14). Saganuwan and Abdul (15) reported $48.7 \%$ prevalence of malaria among Katcha people in Niger State which they attributed to incessant use of chloroquine (15). It was also reported that in Owerri, the age group $(0-10)$ years had the highest rate of infection (79.31\%) while the age group (41-50) years had the lowest rate of infection $(68.96 \%)$. But in Okigwe the age group (41-50 years) had the highest rate of infection (90.32\%) while age group (0-10 years) had the lowest rate of infection $(80-76 \%)(11)$

Malaria causes wide spread premature death and suffering imposing financial hardship on poor household and holds economic growth and development in living standards (12). The rapid spread of resistance to antimalarial drugs present a potentially devastating threat. For decades, chloroquine was the main drug used, but increasing resistance forced its replacement in parts of Asia and South America during the 1980s, and in the 1990 African countries are starting to follow suit (12). In Eastem Nigeria, 40$60 \%$ of malaria cases have been reported not to respond to treatment with the drug (3). The persistence of malaria as a public health problem is partly as a result of resistance of malaria parasites to antimalarial drugs and to insecticides by anopheles mosquitoes (16). Although, Saganuwan and Yatswako (17) reported that the keys to its eradication remains improvement in the standard of living, reduction in poverty, enlightenment campaign by Nongovernmental Organization (NGO) and the use of polypharmacy in malarial chemotherapy (17).

However in view of the prevalence, holoendemicity, epidemicity of malaria and its devastating consequences on economy of highly endemic countries like Nigeria, there is need to find out the distribution of malaria in each geopolitical zones of Nigeria. Bearing in mind that Makurdi in which University of Agriculture Health Centre is located is among malarial zones. Hence, the present study was aimed at determining the epidemicity of malaria in University of Agriculture Health Centre, Makurdi, Benue State, Nigeria using age and sex as factors under consideration.

\section{MATERLALS AND METHODS}

The sampling station was University of agriculture Makurdi Health Centre located at North-core of the 
University. The University is located about $10 \mathrm{~km}$ away North of Makurdi town and about $1 \mathrm{~km}$ from upper part East of River Benue. The vegetation of the University is typical that of savannah region in tropic located in the middle belt of Nigeria. The University has network of streams apart from being closed to river Benue. All the data of malarial cases registered, identified and diagnosed using clinical signs like paroxysm of fever, loss of appetite, headache, lassitude, muscle pains, chills, thirst, nausea, vomiting, delirium and convulsion in children as well as microscopy were collected. The period under review is from January 1998 to December 2005. Malarial cases for each year were sorted out from other cases as the data of males for each year were sorted out from those of females. Data were sorted according to age groups $0-9,10-19,20-29,30-39,40-49,50-59,60-69$, their data for each year under review. The actual numbers of the affected males and females in their respective age groups for each particular year as well as their grand total for each year starting from January 1998 to December 2005 were determined.
Statistical Analysis - Table, graph and pie chart were used to analyze the results (18). Significant levels of differences between the values of males and females as well as among all the age groups were determined at $5 \%(19)$

\section{RESULTS}

Out of 8,992 malaria cases registered between January 1998 to December 2005, nine hundred and twenty eight (928), 886, 1096,1076, 913,1158,1360, 1575 suffered from malaria in the years 1998, 1999, 2000, $2001,2002,2003,2004$ and 2005 respectively. The highest malaria incidence was in 2005, and the lowest in 1999. When considering the epidemicity of malaria within the total period under review, a total of 4503 $(50.5 \%)$ of malaria cases were males as differentiated from those of females 4414 (49.5\%), signifying higher distribution in males as compared to females. But in 2005 alone a total of 813 malaria cases were against males signifying the year more males were affected that year. In all other years under review males had higher distribution of malaria as compared to females see table 2 below and fig. 1 .

Sex wise, the females had low distribution throughout the period under review as compared to males who had higher distribution, although in 2001, the gap of distribution between males and females was wider fig. 1.

Table 1. Yearly Incidence of Malaria by sex

\begin{tabular}{|c|c|c|c|c|c|c|c|c|c|c|c|c|c|c|c|c|}
\hline Year & \multicolumn{2}{|c|}{1998} & \multicolumn{2}{|c|}{1999} & \multicolumn{2}{|c|}{2000} & \multicolumn{2}{|l|}{2001} & \multicolumn{2}{|c|}{2002} & \multicolumn{2}{|c|}{2003} & \multicolumn{2}{|c|}{2004} & \multicolumn{2}{|c|}{2005} \\
\hline$\overline{\text { Sex }}$ & $\bar{M}$ & $\mathbf{F}$ & $\mathbf{M}$ & F & $\mathrm{M}$ & $F$ & $\bar{M}$ & $\bar{F}$ & $\mathrm{M}$ & $F$ & $\bar{M}$ & $\mathbf{F}$ & $\bar{M}$ & $F$ & $\mathrm{M}$ & $\mathrm{F}$ \\
\hline Age & & & & & & & & & & & & & & & & \\
\hline $0-9$ & 110 & 101 & 103 & 65 & 120 & 122 & 152 & 130 & 81 & 74 & 124 & 120 & 151 & 149 & 177 & 175 \\
\hline $10-19$ & 102 & 95 & 74 & 70 & 100 & 110 & 90 & 63 & 68 & 56 & 90 & 86 & 113 & 103 & 142 & 139 \\
\hline $20-29$ & 150 & 135 & 235 & 150 & 263 & 175 & 241 & 191 & 262 & 246 & 262 & 248 & 297 & 271 & 325 & 290 \\
\hline $30-39$ & 113 & 116 & 72 & 114 & 100 & 102 & 110 & 96 & 66 & 57 & 116 & 107 & 141 & 132 & 167 & 158 \\
\hline $40-49$ & 4 & 2 & 1 & 2 & 1 & - & - & - & 2 & 1 & 2 & 1 & 3 & - & - & - \\
\hline $50-59$ & - & - & - & $=$ & 2 & $=$ & $=$ & 3 & - & - & 2 & - & - & - & 2 & - \\
\hline $60-69$ & $=$ & $=$ & $=$ & - & & 1 & - & - & $=$ & $=$ & - & - & - & - & & \\
\hline Total & 479 & 449 & 485 & 401 & 586 & 510 & 593 & 483 & 479 & 434 & 596 & 562 & 705 & 655 & 813 & 762 \\
\hline $\begin{array}{l}\text { Grand } \\
\text { total }\end{array}$ & 928 & & 886 & & 1096 & & 1076 & & 913 & & 1158 & & 1360 & & 1575 & \\
\hline
\end{tabular}


Table 2:

The Distribution of malaria between males and females for the period under review

\begin{tabular}{|r|r|r|}
\hline Year & Males & Female \\
\hline 1998 & 479 & 449 \\
\hline 1999 & 485 & 401 \\
\hline 2000 & 586 & 510 \\
\hline 2001 & 593 & 483 \\
\hline 2002 & 479 & 434 \\
\hline 2003 & 596 & 562 \\
\hline 2004 & 705 & 655 \\
\hline 2005 & 813 & 762 \\
\hline
\end{tabular}

Fig. 1 Graphical distribution of malaria using sex for the period under review

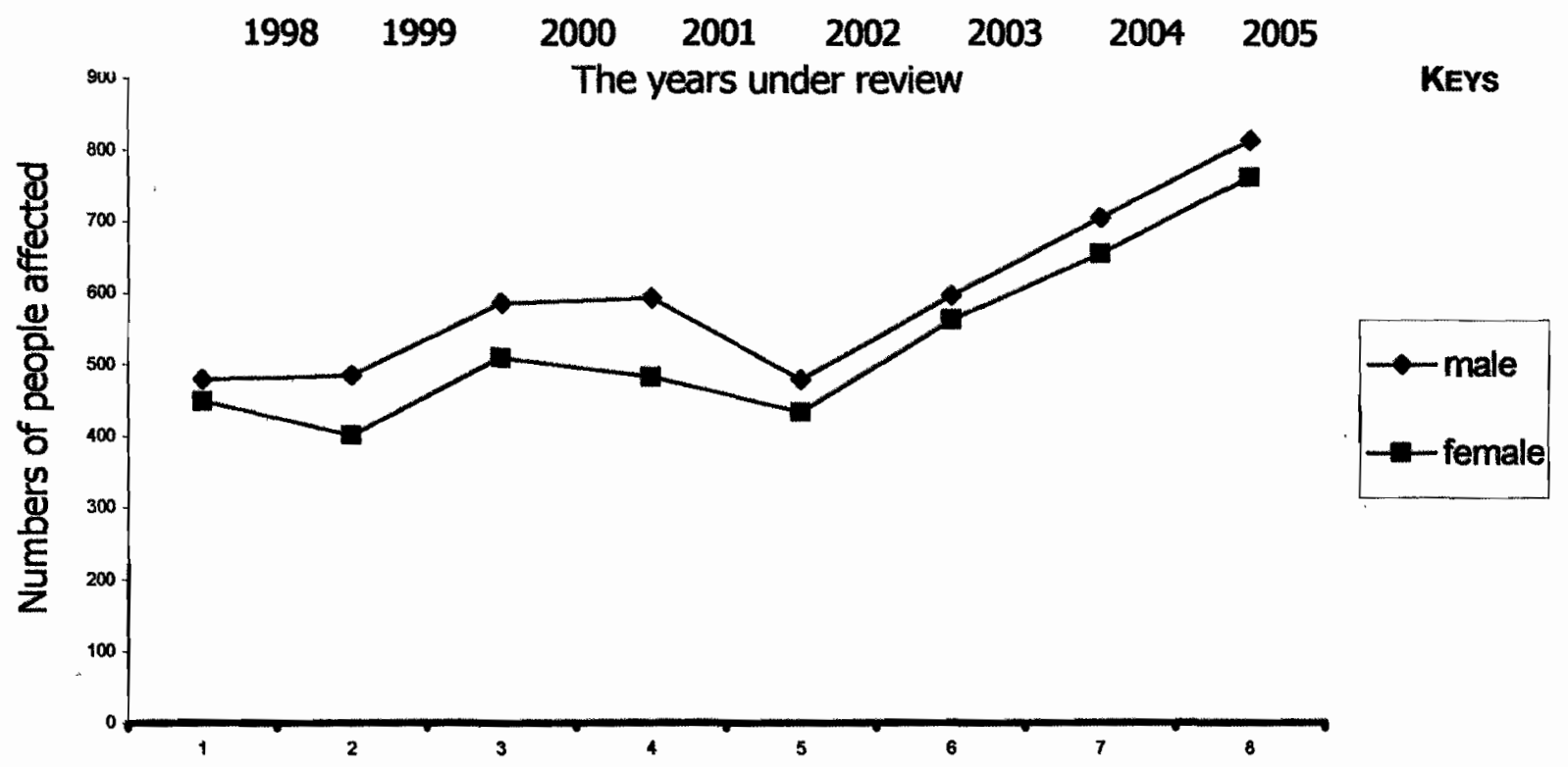

Age wise, malaria patients in age group $(20-29)$ had the highest incidence $3,741(41.6 \%)$ as those of age group $(60-69)$ had the lowest $1(0.00 \%)$. But those in age groups (0-9), (10-19), (30-39), (40-49), (50-59), (60-69), had malaria distribution of 1954 (21.7\%),
$1501(16.7 \%), 1769(19.9 \%), 19(0.00 \%)$ and 7 $(0.00 \%)$ respectively. Although for a particular year the males in age group of (20-29) had the highest distribution 325 as against the females in the age group $(60-69)$ who had the lowest (table 1 above) 
Fig. 2: Pie chart distribution of malaria using age for the period under review

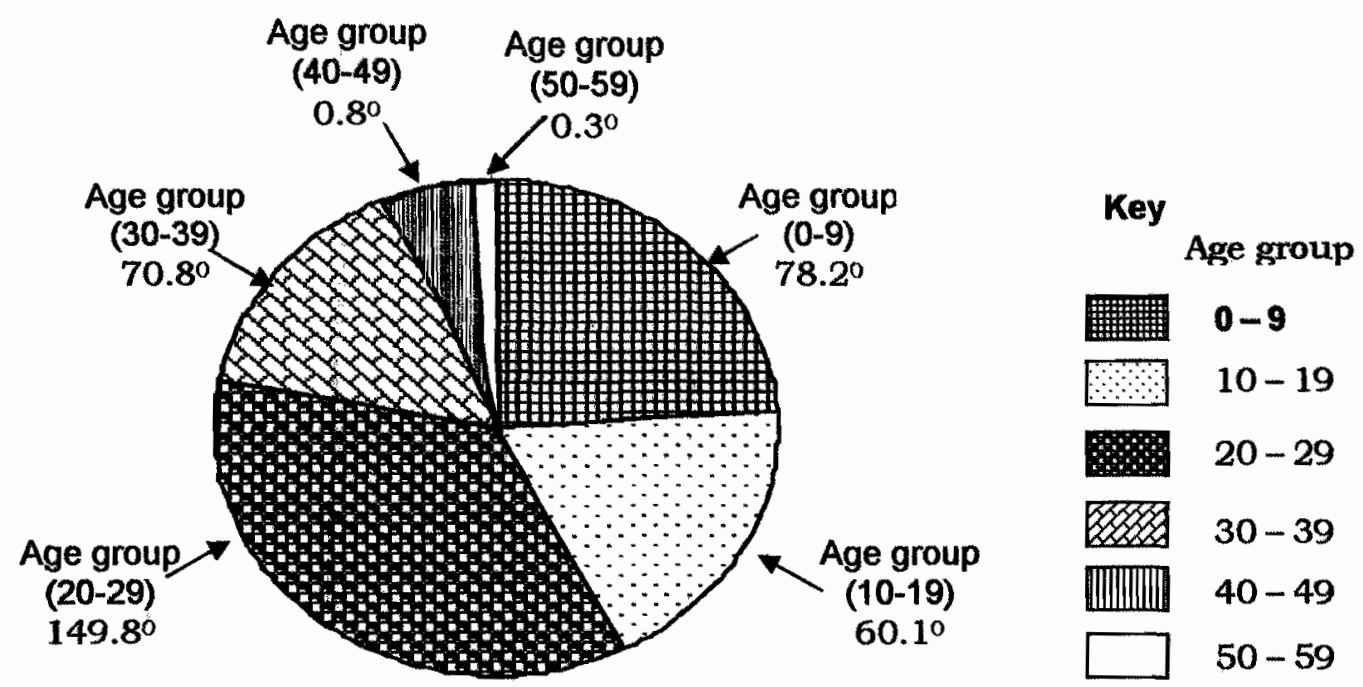

Age wise, the malarial patients within the age group (20-29) had the highest distribution $\left(149.80^{\circ}\right)$ followed by those in age group (0-9), which had $\left(78.20^{\circ}\right)$ then age group (30-39), which had $\left(70.80^{\circ}\right)$. But those in age group (10-19) had $\left(60.10^{\circ}\right)$ as those in age groups (40-49), (50-59), and $(60-69)$ had $\left(0.80^{\circ}\right),\left(0.30^{\circ}\right)$ and $\left(0.0^{\circ}\right)$ respectively. There was association between males and females distribution as $5.4 \%$ more of males were affected when compared.

\section{DISCUSSION}

The highest epidemicity of malaria, was experienced in 2005 (table 1). Males were more affected than females (table 1, Fig. 1). Those in age group (20-29) had the highest incidence. This is a (Fig. 2) clear confirmation of the report of other workers $(6,7,8,9)$ that each year $300-500$ million people living in the tropics and subtropics became infected with malaria and that about 1.5 billion live in the regions where malaria is endemic of which Africa is one of them. Our finding is also supported by another report of (12) that the resurgence of malaria in Africa contrasts dramatically with the global decline in mortality since $1900(6,7,8,9)$. Our report is further supported by (4) that in Nigeria malaria affects more people than it did in 60s and that Federal Ministry of Health reported that one in four people suffered from malaria at one time or the other. However, our finding was confirmed by the report of (14) that the number of people affected in Nigeria is growing remorselessly as Saganuwan and Abdul (15) reported $48.7 \%$ prevalence in the Middle Belt (15). Our finding of highest epidemicity of malaria in University of Agriculture Makurdi health centre in 2005 is further supported by the report of (10) that about $93 \%$ of the 550 million people living in Africa are at risk of malaria and over $90 \%$ of the $300-500$ million clinical cases are reported from Africa (10). 
Nevertheless, the higher epidemicity amongst males (table 2, fig. 1) as well as the highest distribution among those of age groups (20-29) followed by (0-9), then (30-39) and (10-19) may suggest the devastating economic consequence of malaria. Because those in the age groups (20-29) and (30-39) are adults who are suppose to be energetic and responsible for one family responsibility or the other as many Africans marry early. This is supported by the report of (12) that malaria causes wide spread premature death and suffering imposing financial hardship on poor household and holds economic growth and development in living standards (10). Our finding is further supported by the report of (4) that $50 \%$ of Nigerian population experience at least one episode of malaria each year, the financial implication could amount to $\$ 400$ million every year (13),

Nonetheless, the higher epidemicity amongst males (table 1, fig. 1) and the highest distribution amongst those of age group (20-29) may be suggestive of more exposure of those people to mosquito as males always go out to earn their living so also those in age group (20-29) as some of them may be students and juniof staff. But lowest distribution (fig.2) in those of age group (60-69) and very low epidemicity in those of age groups (40-49) and (50-59) (fig.2) may be suggestive of decrease exposure of those people to mosquito which consequently leads to low epidemicity. Connotatively the higher the age the lower the chance of malarial infection and the lower the age, the higher the chance of malarial infection which i may refer to as "beneficial and risky reverse opportunities in favour of the old ones as against the young ones" although pending on the environment. There was association between males and females' distributions as $\mathbf{5 . 4 \%}$ more of males were affected when compared. Furthermore, there was no association among malarial patients of all the age groups.

If nothing is done to fight against high malaria endemicity in university of Agriculture Makurdi health centre, the higher malaria epidemicity between men and females as well as higher distribution among those of the age group (20-29) will continue to be on increase.

\section{CONCLUSION}

Our findings revealed highest malaria distribution in 2005; males experienced higher epidemicity through out the period under review. But generally, the young ones experienced higher malaria infection rate than the old ones because of possible more exposure of young ones to mosquito as compared to the old ones. The phenomenon is refer to as "beneficial and risky reverse opportunities in favour of the old ones on one side as against the young ones on the other side. This may however depend on the environment.

\section{RECOMMENDATTON}

It is recommended that mosquito nets be used regularly. NGOs should intensify efforts at the control programme to face the global challenges imposed by high malaria prevalence. There should be good water drainages in the environment where there are water bodies, bush clearing and health education should be 
embarked upon by Community Extension Worker (CHEW) on the importance of environmental cleanliness as being embarked upon by Benue State Government at the end of every month.

\section{REFERENCES:}

1. Smyth, J. D. Sporozoea: Haemosporina: malaria: basic biology. Animal parasitology. Cambridge low price eds. pp, 109-111. (1996).

2. Laveran, A. Pludism In: (J. W. Martins) Trans. The New Sydenham society. London, p, 197 (1893).

3. Ukoli, F.M.A. Introduction of parasitology in Tropical Africa: John Wiley \& Sons Ltd, Chichestes. P, 404 (1984).

4. Ukoli, F.M.A. The Biology and natural history of malaria. Proceedings of the fifth annual convention and scientific assembly. Archives of Ibadan Medicine Vol. 1(2) 35 36. (2003).

5. Katzung, B.G. Antiprotozoal drugs: Treatment of malaria. Basic and clinical pharmacology. Inernational eds. McGraw hill Inc. pp, 864-873. (2004).

6. WHO. Malaria action: programme: severe and complicated malaria. Trans Roy soc. Med. \& Hyg. (809supplement):1-50. (1986).

7. WHO New Perspective for malaria diagnosis, Geneva (2001).

8. Castelli, F; Natteelli, A; Calligaris, S.; Gulleta, M.; El-hamad, I.; Scolari, C.; Chatel, G.; Carosi, B. Malaria in migrants In: parasitologia 41:2671-265 (1999).

9. Ruth, S. N. and Fedel, Z. Malaria vaccine based on a sporozoite antigen. The New
England Journal of Medicine, 336(2): 128129 (1997)

10. WHO, Vector control for malaria and other mosquito-borne diseases. Tech. Rep. Ser. Pp, 91, 857 (1995).

11. Ukpai, O. M. and Ajoku, E.I. The prevalence of malaria in Okigwe and Owerri Areas of Imo State. The Nig. J. of parasitol. Vol. 22 (192), pp, 43-48 (2001).

12. WHO Rolling back Malaria. The World Health Report, pp 49 (1999)

13. Ukoli, F.M.A. Prevention and control of parasitic diseases in tropical Africa: The main issues: University press Plc, Ibadan, pp, 199 (1992)

14. Knell, Malarial Oxford University press, Oxford, pg 94 (1991).

1. Saganuwan, S. A. and Abdul, M. S. (The prevalence of malaria in Katcha, Niger State, Nigeria. Afr. J. Eper. Microbil 7(3) 13 (2006).

16. Agomo, P. U. Antimalarial medicinal plants: The need for caution. Clinical medicine 4:226. (1991).

17. Saganuwan, S. A. and Yatswako, S. Malaria parasites of clinical and laboratory importance - An update. Proceedings of Annual Conference of IRDI Research and Development Network. Vol.1, No. 1 Jun. 28-29, 2006: Conference Centre, University of Calabar, Nigeria. pp 52-56 (2006).

18. Frank, H. and Althoen, S., Organisation and description of data Statistics; Concepts and applications, Cambridge University Press, New York, USA, pp. 2-73 (1995). 
19. Petrie A. and Watson, P. Hypothesis test-the Blackwell Science Ltd. Uk, PP 78-85 t-test comparing one or two means. Statistics (2002).

for Veterinary and Animal Science

Visit our website http://www_ajol.info/journals/ajem 